\title{
Voltammetric Study of the Copper Pentacyanonitrosylferrate Adsorbed on the Silica Modified with a Poly(propylene)imine Hexadecylamine Dendrimer for Determination of Nitrite
}

\author{
D. R. do Carmo, S. Gabriel Jr., D. R. Silvestrini, U. O. Bicalho, and L. R. Cumba \\ Departamento de Física e Química, Faculdade de Engenharia de Ilha Solteira, Universidade Estadual Paulista (UNESP), \\ Avenida Brasil Centro 56, 15385-000, Ilha Solteira, SP, Brazil \\ Correspondence should be addressed to D. R. do Carmo, docarmo@dfq.feis.unesp.br
}

Received 4 December 2011; Revised 11 February 2012; Accepted 19 February 2012

Academic Editor: Valentin Mirceski

Copyright ( $) 2012$ D. R. do Carmo et al. This is an open access article distributed under the Creative Commons Attribution License, which permits unrestricted use, distribution, and reproduction in any medium, provided the original work is properly cited.

Poly(propylene)imine hexadecylamine dendrimer (DAB-Am-16) was anchored on the surface of 3-chloropropylsilyl silica gel and subsequently interacted with copper nitroprusside. The composite was characterized by infrared (FTIR), energy dispersive $\mathrm{X}$-ray (EDX), and cyclic voltammetry. The above techniques confirmed the successful anchoring of the dendrimer on the silica gel modified surface and its interaction with copper nitroprusside. The cyclic voltammogram of CuNPSD was found to exhibit two redox couples with $\left(E^{\theta^{\prime}}\right)_{1}=0.30 \mathrm{~V}$ and $\left(E^{\theta^{\prime}}\right)_{2}=0.78 \mathrm{~V}$ versus $\mathrm{Ag} / \mathrm{AgCl}\left(\mathrm{KCl}=1.0 \mathrm{~mol} \mathrm{~L}^{-1} ; v=20 \mathrm{mV} \mathrm{s}^{-1}\right)$ attributed to the redox processes $\mathrm{Cu}^{(\mathrm{I})} / \mathrm{Cu}^{(\mathrm{II})}$ and $\mathrm{Fe}^{(\mathrm{II})}(\mathrm{CN})_{5} \mathrm{NO} / \mathrm{Fe}^{(\mathrm{III})}(\mathrm{CN})_{5} \mathrm{NO}$, respectively. The CuNPSD-modified graphite paste electrode was found to show a linear response of $5.0 \times 10^{-4}$ to $9.0 \times 10^{-3} \mathrm{~mol} \mathrm{~L}^{-1}$ for nitrite determination with a detection limit (DL) of $3.8 \times 10^{-4} \mathrm{~mol} \mathrm{~L}^{-1}$ and an amperometric sensitivity of $25.0 \mathrm{~mA} / \mathrm{mol} \mathrm{L}^{-1}$. The CuNPSD-modified graphite paste electrode was found to show a good electrochemical stability and an excellent response to the electrocatalytic oxidation of sodium nitrite.

\section{Introduction}

Dendrimers are monodispersed macromolecules with wellknown nanometer dimensions, especially their symmetrical shape of its highly branched and spherical structure [1]. This class of polymers has received considerable interest with possible applications in micelles $[2,3]$ and the encapsulation of substances [4-6] such as liquid crystals [7]. In electroanalysis [8-10] dendrimers have particular applications in sensors [11], electroluminescent devices [12, 13], and catalysts [14, 15] due to their unique structure and properties. However, very little is known about the interaction of these compounds with nitroprusside.

Nitroprusside- (NP-) based compounds have been, in recent years, the target of a large number of works mainly in the areas of electrochemistry $[16,17]$ and electroanalysis $[18,19]$. This is due mainly to their high electrophilic character and reducibility capacity attributed to the $\mathrm{NO}^{+}$ligand primarily responsible for the reactions of NP ions making these compounds highly interesting not only from the physicochemical standpoint through the coordination properties of groups nitrosyl [20] but also because of their important biological role primarily as a source of nitric oxide [21]. Some studies have been carried out on the use of nitroprusside ions as electron mediator in the electrocatalysis of substances of biological interest $[19,22,23]$.

In the present study, the poly(propylene)imine hexadecylamine dendrimer (DAB-Am-16) was anchored [24] on the surface of 3-chloropropylsilyl silica gel generating the composite (SD). DAB-Am-16 consists of a polar core and an apolar periphery [25], there are three generations of branches, and the outermost shell is composed of $16-\mathrm{NH}_{2}$ groups. The chelating capacity of such amine dendrimers can be used to adsorb metal ions in the environmental and biological samples in organic or aqueous medium because amine dendrimers are macrochelating agents for transitions metals. Silica 
was chosen as substrate for anchoring DAB-Am-16 due to the high stability of complexes formed that permits their multiple uses in preconcentration and separation processes.

In this context, this work have as purpose to prepare dendrimer supported on the silica gel surface to an analytical and electroanalytical application, using a direct and facile procedure. The idea is to combine the ion exchange properties with good ionic conductor, and this combination will facilitate charge transfer between CuNP and SD due to the cation diffusion within the CuNP mediated by SD component.

Subsequent to being generated, the SD was made to adsorb cupric ions, the resulting material being CuSD, which then reacted with sodium nitroprusside (NP) to form a binuclear complex on the surface of silica (SD). A rigorous cyclic voltammetry study of this new compound formed, CuNPSD, was carried out to optimize the main electrochemical parameters and thus establish a system for the graphite paste electrode in which the dendrimer, modified on its surface, will be employed in the electrocatalytical determination of sodium nitrite. Nitrite, on the other hand, has a biological importance in environment-related questions, while, in the area of medicine, it serves as vasodilator with a direct action on smooth muscles and thus directly affects the levels of blood pressure in an individual [26]. In nature, nitrite ions are produced by the photolysis of nitrate ions and photodegradation of humic substances found mainly in aquatic environments [27].

The literature describes various methods used in determining these compounds : titration, which involves reactions with potassium permanganate [28] or iodine [29], UV-VIS spectrophotometry [30], chromatographic methods such as HPLC [31], and electrochemical methods involving redox reactions [32]. Among these methods, the electrochemical methods are considered to be among the best because of their low cost and quick analysis [27] especially those in which modified electrodes are employed.

\section{Experimental}

2.1. Formation of DAB-Am-16 on the Surface of Silica Gel. $1.0 \times 10^{-3}$ mol of DAB-Am-16 was added to $10 \mathrm{~g}$ of 3chloropropylsilyl silica gel suspended in $25 \mathrm{~mL}$ of methanol. The suspension was kept under reflux for $48 \mathrm{hrs}$. The resulting solid was then separated using a thin sintered plate funnel and washed several times with the solvent. The solid phase was properly packaged and transferred to a Soxhlet extractor and washed several times with dry toluene in order to eliminate excess unbonded dendrimer. The resulting material was dried at $80^{\circ} \mathrm{C}$ and kept in a vacuum desiccator in the dark. For brevity, the resulting composite was labeled SD.

\subsection{Formation of Binuclear Complex with Modified Silica Gel} (CuNPSD). The Binuclear complex was prepared according to the procedure described in the literature [24] with some modifications: $1.0 \mathrm{~g}$ of modified silica (SD) was immersed in $25 \mathrm{~mL}$ of a $1.0 \times 10^{-3} \mathrm{~mol} \mathrm{~L}^{-1}$ cupric ion $\left(\mathrm{Cu}^{2+}\right)$ solution $(99 \%(\mathrm{v} / \mathrm{v})$ acetone). This mixture was stirred for 30 minutes at room temperature, and the solid phase was filtered and washed with deionized water thus forming the CuSD. After thorough washing, the CuSD was added to a $1.0 \times 10^{-3} \mathrm{~mol} \mathrm{~L}^{-1}$ solution of the electroactive sodium nitroprusside compound, $\mathrm{Na}_{2}\left[\mathrm{Fe}(\mathrm{CN})_{5} \mathrm{NO}\right]$. The resulting material was washed with enough deionized water and the compound obtained labeled as CuNPSD. A schematic presentation of this synthesis is represented by Figure 1.

2.3. Characterization Measurements. The spectra in the infrared region were obtained by a Nicolet 5DXB FT-IR spectrometer (Nicolet Instruments, Madison, WI). The pastils for analysis were prepared using $150 \mathrm{mg}$ of previously dried $\mathrm{KBr}$ PA of the Synth brand and $1.5 \mathrm{mg}(1.0 \%(\mathrm{w} / \mathrm{w}))$ of each sample. A minimum of 64 "scans" with a resolution of $\pm 4 \mathrm{~cm}^{-1}$ in a band of 4000 to $400 \mathrm{~cm}^{-1}$ was used. EDX measurements were taken with a Jeol JTSM T-330 electron microscope. The samples of about 20 to $30 \mathrm{~nm}$ thickness were metallized in a BAL-TEC SCD 050 sputter for $120 \mathrm{~s}$. The cyclic voltammetry readings were obtained by potentiostat of Microquímica (MQPG-01) on a scale ranging from -0.1 to $1.2 \mathrm{~V}$ (versus $\mathrm{Ag} / \mathrm{AgCl}$ ). The electrochemical system was composed of three electrodes: a working electrode (internal diameter $0.5 \mathrm{~mm}$ ) of graphite paste modified with $20 \%$ CuNPSD, $25 \mu \mathrm{L}$ Nujol, as reference electrode $\left(\mathrm{Ag} / \mathrm{AgCl}_{(s)}\right)$, and an auxiliary electrode made of platinum. In the electrochemical cell, the nitrite solutions used in voltammetric experiments were prepared immediately before use and were deaerated with purified nitrogen.

\section{Results and Discussion}

Figure 2 illustrates the infrared spectra of the NP (a) and CuNPSD (b). The CuNPSD was observed to exhibit two absorption bands at $2196 \mathrm{~cm}^{-1}$ and $1953 \mathrm{~cm}^{-1}$ (Figure 2(b)), which confirmed the formation copper pentacyanonitrosylferrate on the surface of the SD (CuNPSD). The absorption bands at 2211 and $1960 \mathrm{~cm}^{-1}$, attributed to the stretching of " $v{ }_{s}(\mathrm{CN})$ and " $v{ }_{s}(\mathrm{NO})$, were found to be in good agreement with values for transition metal pentacyanoferrates $[24,33,34]$ reported in the literature. A close comparison of the " $v{ }_{s}(\mathrm{CN})$ and " $v{ }_{s}(\mathrm{NO})$ band shifts and those obtained for sodium nitroprusside (NP) confirms a bathochromic shift of the former relative to the latter (Figure 2(a)), thus characterizing the formation of the binuclear complex on the silica surface (SD).

Figure 3 depicts the EDX spectra of SD (a) and CuNPSD (b). The absence of $\mathrm{Cl}$ in the SD is evident for the complete reaction of the functionalized silica and the dendrimer. On the other hand, the presence of $\mathrm{Fe}, \mathrm{Cu}$, and $\mathrm{N}$ in the EDX obtained for CuNPSD is easily perceived as expected. These data support the formation of copper on the surface of silica gel modified with the dendrimer. A complementary and detailed characterization of SD using nuclear magnetic resonance in the solid state $\left({ }^{29} \mathrm{Si}\right.$ and $\left.{ }^{13} \mathrm{C} \mathrm{NMR}\right)$ has been performed and recently published [24].

3.1. Electrochemical Characterization of CuNPSD. The cyclic voltammogram $(\mathrm{CV})$ of the CuNPSD-modified graphite 


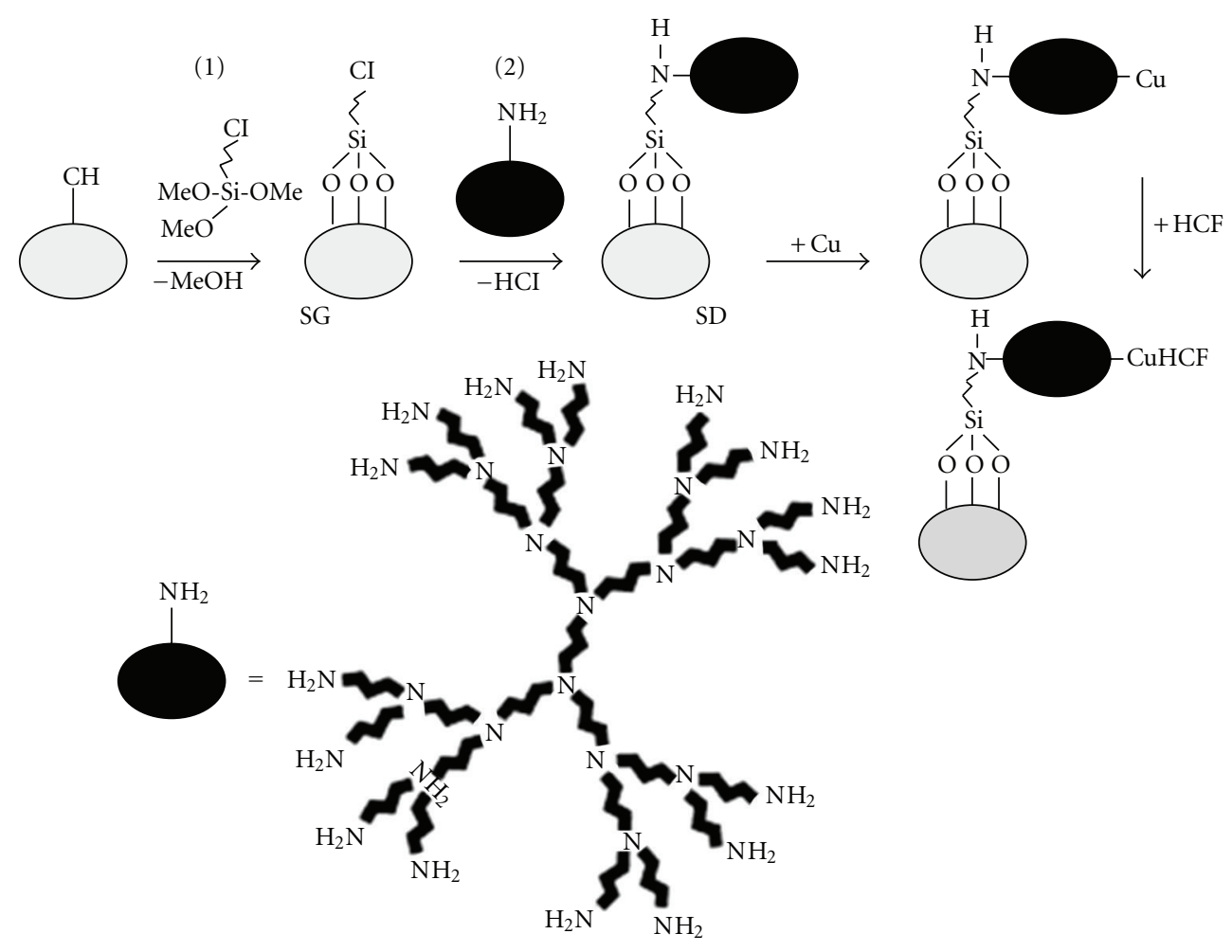

(DAB-Am-16)

HCF: Potassium hexacyanoferrate

FIgURE 1: Schematic representation of the stages in the modification process of CuNPSD.

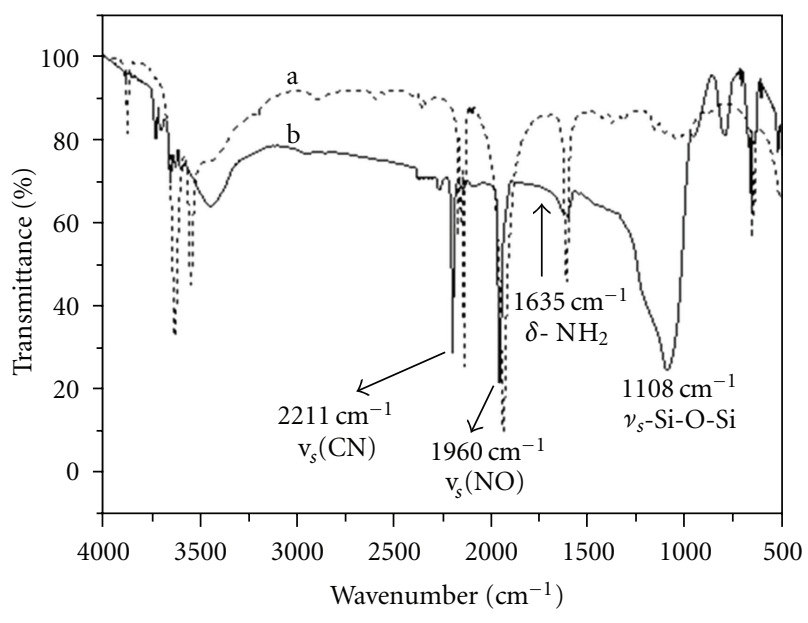

FIGURE 2: FTIR of (a) NP and (b) CuNPSD.

paste electrode was found to exhibit two redox couples, I and II, as illustrated in Figure 4(a) (dashed line). The obtained formal potentials, $\left(E^{\theta \prime}\right)_{1}=0.30 \mathrm{~V}$ and $\left(E^{\theta \prime}\right)_{2}=$ $0.78 \mathrm{~V}$ versus $\mathrm{Ag} / \mathrm{AgCl}_{(s)}$, were attributed to redox processes $\mathrm{Cu}^{(\mathrm{II})} / \mathrm{Cu}^{(\mathrm{II})}$ and $\mathrm{Fe}^{\mathrm{III}}(\mathrm{CN})_{5} \mathrm{NO} / \mathrm{Fe}^{(\mathrm{III})}(\mathrm{CN})_{5} \mathrm{NO}$ respectively,

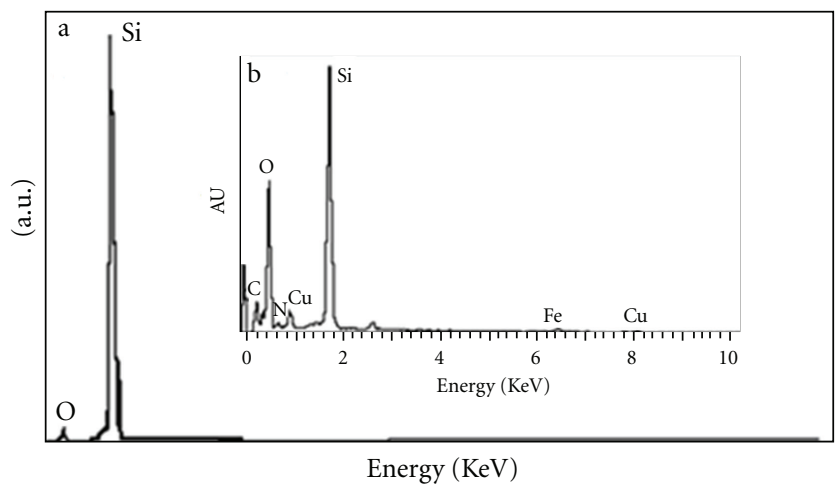

FIGURE 3: Energy dispersive X-ray (EDX) analysis of (a) SD and (b) CuNPSD.

as described by (1) and (2), where $\mathrm{K}^{+}$: on was used for charge balance.

$$
\begin{aligned}
\mathrm{K}_{2} \mathrm{Cu}^{(\mathrm{I})}\left[\mathrm{Fe}^{(\mathrm{II})}(\mathrm{CN})_{5} \mathrm{NO}\right] \rightleftarrows & \mathrm{KCu}^{(\mathrm{III})}\left[\mathrm{Fe}^{(\mathrm{III})}(\mathrm{CN})_{5} \mathrm{NO}\right] \\
& +\mathrm{K}^{+}+\mathrm{e}^{-}(0.30 \mathrm{~V}) \\
\mathrm{KCu}^{(\mathrm{II})}\left[\mathrm{Fe}^{(\mathrm{II})}(\mathrm{CN})_{5} \mathrm{NO}\right] \rightleftarrows & \mathrm{Cu}^{(\mathrm{II})}\left[\mathrm{Fe}^{(\mathrm{III})}(\mathrm{CN})_{5} \mathrm{NO}\right] \\
& +\mathrm{K}^{+}+\mathrm{e}^{-}(0.78 \mathrm{~V}) .
\end{aligned}
$$




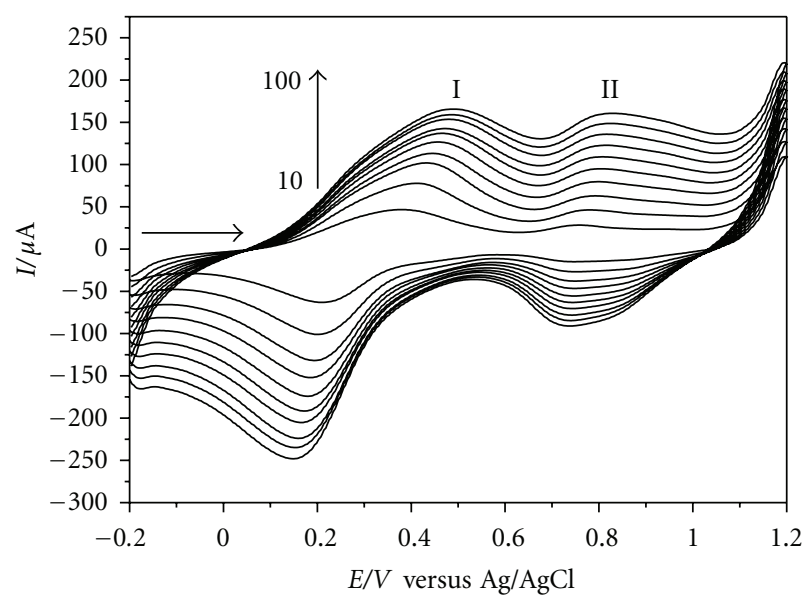

(a)

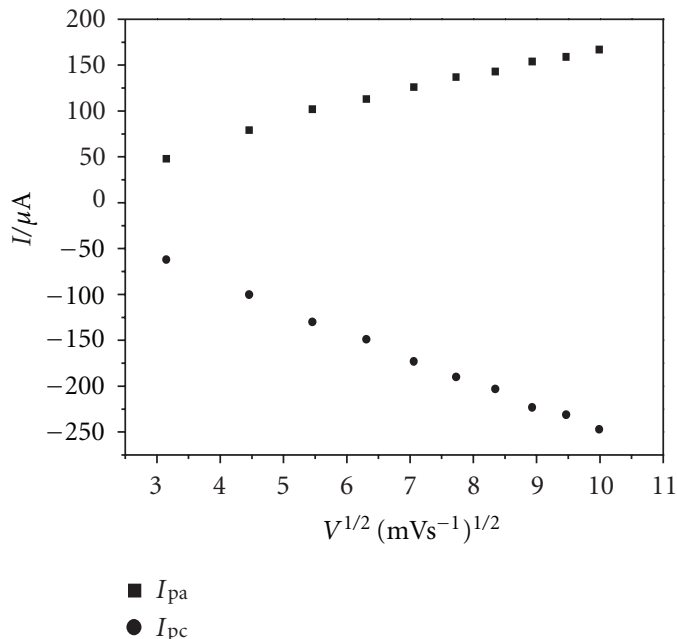

(b)

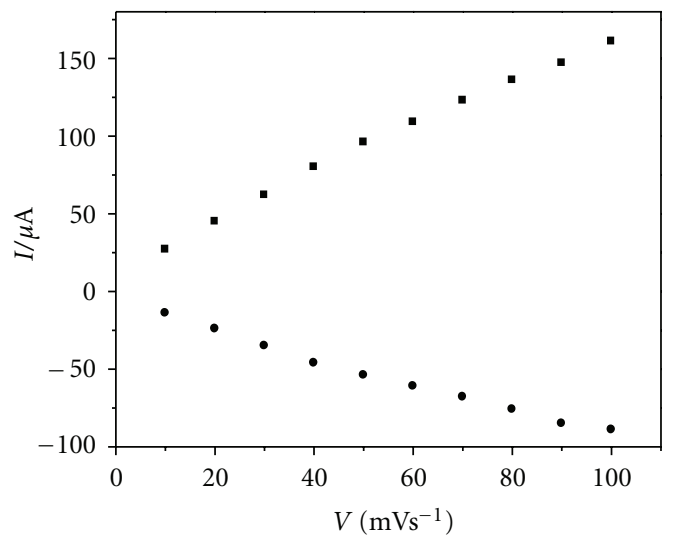

- $I_{\mathrm{pa}}$

- $I_{\mathrm{pc}}$

(c)

FIGURE 4: (a) Cyclic voltammogram of CuNPSD for different scanning rates: $10-100 \mathrm{mV} \mathrm{s}^{-1}\left(\mathrm{KCl}=1.0 \mathrm{~mol} \mathrm{~L}^{-1}, \mathrm{pH}^{-}=7.0\right)$. (b) Linear dependence of the anodic and cathodic current intensity with the square root of scan rate (peak I). (c) Linear dependence of the anodic and cathodic current intensity with the scan rate (peak(II)).

The redox process I illustrated in Figure 4(a) was attributed to the redox couple $\mathrm{Cu}^{(\mathrm{I})} / \mathrm{Cu}^{(\mathrm{II})}$, which is compatible to that observed by Shankaran and Narayanan [35] and De Sá et al. [36], while the redox process II is representative of the process $\left[\mathrm{Fe}^{(\mathrm{II})}(\mathrm{CN})_{5} \mathrm{NO}\right] /\left[\mathrm{Fe}^{(\mathrm{III})}(\mathrm{CN})_{5} \mathrm{NO}\right]$ on the surface of the SD (2) with values found to be consistent with those reported in the literature for copper nitroprusside [18, 37, 38]. Studies on the voltammetric behavior of CuNPSD in different supporting electrolytes $(\mathrm{LiCl}, \mathrm{NaCl}, \mathrm{KCl}$, and $\mathrm{NH}_{4} \mathrm{Cl}$ ) ascertained that the nature of cations affects not only the current intensity but also the average potentials of the redox process II $\left(E^{\theta}\right)_{2}$ found to shift to more positive potentials according to the following order: $\mathrm{NH}_{4}{ }^{+}>\mathrm{K}^{+}>$ $\mathrm{Na}^{+}>\mathrm{Li}^{+}$. This behavior is quite similar to that observed for Prussian blue [39] thus suggesting that the cavity diameter of the structure of sodium nitroprusside appears to be very close to that found in the literature $(0.32 \mathrm{~nm})$ for similar compounds such as Prussian blue [40]. The nature of anions
$\left(\mathrm{Cl}^{-}, \mathrm{NO}_{3}{ }^{-}, \mathrm{SO}_{4}{ }^{2-}, \mathrm{CLO}_{4}{ }^{-}\right)$was found to hardly affect the average potential of the redox couples I and II. Table 1 lists the values of the mean/average potentials presented and the main electrochemical parameters of the above-mentioned compound.

Figure 4(a) presents also cyclic voltammograms of the CuNPSD-modified graphite paste obtained for different scanning speeds. The redox process I found a linear dependence of the anode and cathode peaks on the square root of scan rate, thus characterizing a diffusion-controlled process, while, for the redox process II, there was a linear dependence on scan rate, hence characterizing an adsorptive process [41], as illustrated by the graphs in the Figures 4(b) and 4 (c), respectively. It was observed that the redox peak I of $\mathrm{CV}$ has $\triangle E p>200 \mathrm{mV}\left(v=100 \mathrm{mV} \mathrm{s}^{-1}\right)$, because the kinetics of electrons transfer at the electrode surface is not fast enough. This may be due to the difficulty of diffusion of species through the electrolyte-electrode interface solution 
TABLE 1: Relationship between the diameter of hydrated cations and the electrochemical parameters of CuNPSD (electrolyte 1.0 mol L ${ }^{-1} ; v$ $\left.=20 \mathrm{mV} \mathrm{s}^{-1} ; \mathrm{pH}=7.0\right)$.

\begin{tabular}{|c|c|c|c|c|c|c|c|}
\hline Cation & {$\left[I_{\mathrm{pa}} / I_{\mathrm{pc}}\right]_{1}$} & $*\left(E^{\theta}\right)_{1}$ & ${ }^{*} \Delta E p_{1}(\mathrm{~V})$ & {$\left[I_{\mathrm{pa}} / I_{\mathrm{pc}}\right]_{2}$} & $\left(E^{\theta}\right)_{2}$ & $\Delta E p_{2}(\mathrm{~V})$ & $\begin{array}{l}\text { Diameter of } \\
\text { hydrated cation } \\
(\mathrm{nm})^{* *}\end{array}$ \\
\hline$\overline{\mathrm{Li}^{+}}$ & 1.22 & 0.31 & 0.228 & 0.81 & 0.77 & 0.033 & 0.470 \\
\hline $\mathrm{Na}^{+}$ & 1.05 & 0.32 & 0.219 & 0.88 & 0.77 & 0.033 & 0.360 \\
\hline $\mathrm{K}^{+}$ & 0.98 & 0.32 & 0.216 & 0.95 & 0.79 & 0.030 & 0.240 \\
\hline $\mathrm{NH}_{4}^{+}$ & 0.86 & 0.31 & 0.181 & 0.86 & 0.78 & 0.031 & 0.245 \\
\hline
\end{tabular}

${ }^{*} E^{\theta}(\mathrm{V})=\left(E_{\mathrm{pa}}+E_{\mathrm{pc}}\right) / 2 \mathrm{e} \Delta E p(\mathrm{~V})=\left|E_{\mathrm{pa}}-E_{\mathrm{pc}}\right|{ }^{* *}$ Ref. [38].

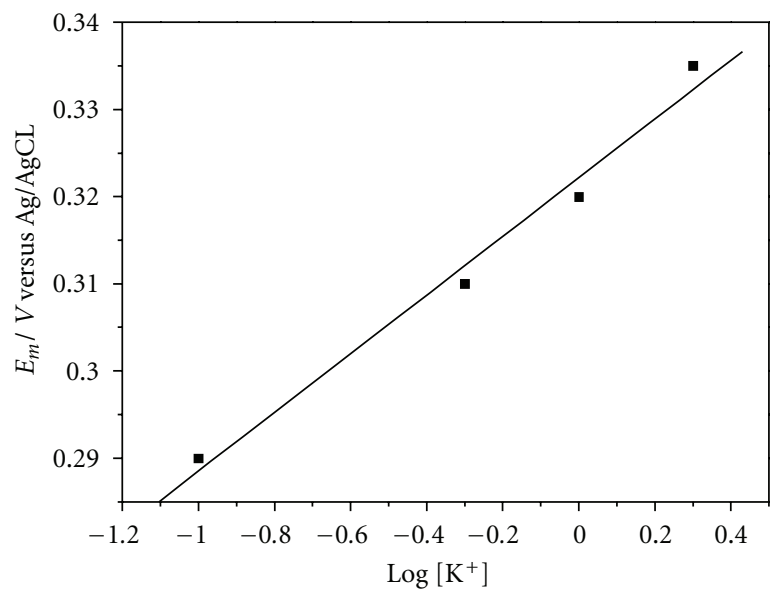

(a)

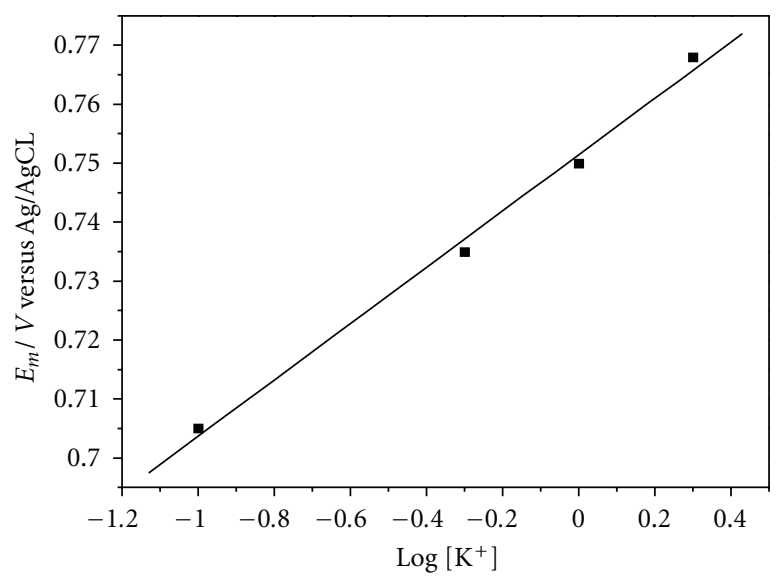

(b)

Figure 5: The dependence of the formal potential of CuNPSD on the logarithms of $\mathrm{K}^{+}$concentration $\left(v=20 \mathrm{mV} \mathrm{s}^{-1}\right)$ : (a) peak I and (b) peak II.

for charge balancing. However, the CV of peak II has $\triangle E p=$ $81 \mathrm{mV}\left(v=100 \mathrm{mV} \mathrm{s}^{-1}\right)$. These results suggest that the two redox processes (I and II) showed distinct behaviors.

The voltammetric studies carried out at different $\mathrm{KCl}$ concentrations $\left(0.1-2.0 \mathrm{~mol} \mathrm{~L}^{-1}\right)$ showed a linear increase of peak potential $\left(E^{\theta \prime}\right)_{1}$ and $\left(E^{\theta \prime}\right)_{2}$ to more positive (anodic) regions as the concentration of electrolyte increased (Figure 5). The estimated slopes of these lines were $34 \mathrm{mV}$ and $47 \mathrm{mV}$ per decade of concentration of potassium ions for the redox processes I and II, respectively, hence indicating a quasi-Nernstian process.

Additionally, a study of the voltammetric behavior of CuNPSD in different hydrogen ion concentrations showed that the average potentials $\left(E^{\theta^{\prime}}\right)$ of the two redox processes remained virtually unchanged in the $\mathrm{pH}$ range between 2 and 8. For high hydrogen ion concentrations or when the $\mathrm{pH}$ attained values below 3 , the formation of a new redox process with average potentials $\left(E^{\theta^{\prime}}\right)_{3}=0.48 \mathrm{~V}$ was found to take place, as shown in Figure 6, a behavior analogous to that shown by Prussia blue. From these studies we conclude that high concentrations of $\mathrm{H}^{+}$ions compete with $\mathrm{K}^{+}$ions in the system redox process forming one or more intermediate species [18]. Another explanation for the above observation is the protonation of the cyanide groups, which alter the electron density of the metal center of $\mathrm{Fe}$ and $\mathrm{Cu}$ in CuNPSD (backbonding).

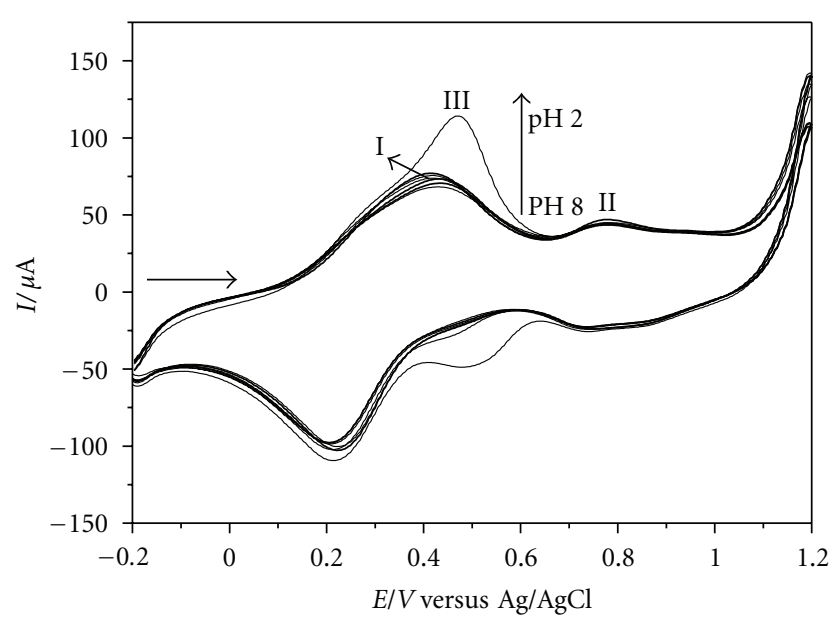

FIGURE 6: Cyclic voltammograms of CuNPSD at different $\mathrm{pH}$ values $(8-2)$.

3.2. Application of CuNPSD in the Determination of Nitrite. In search for an electroanalytical application of CuNPSD, this compound was tested for its voltammetric determination of nitrite using a graphite paste electrode. The CuNPSDmodified graphite paste electrode in the presence of nitrite was investigated in support of the electrolyte chosen previously, $\mathrm{KCl} 1.0 \mathrm{~mol} \mathrm{~L}^{-1}$ at $\mathrm{pH}$ 7.0. Figures $7(\mathrm{c})$ and $7(\mathrm{a})$ 


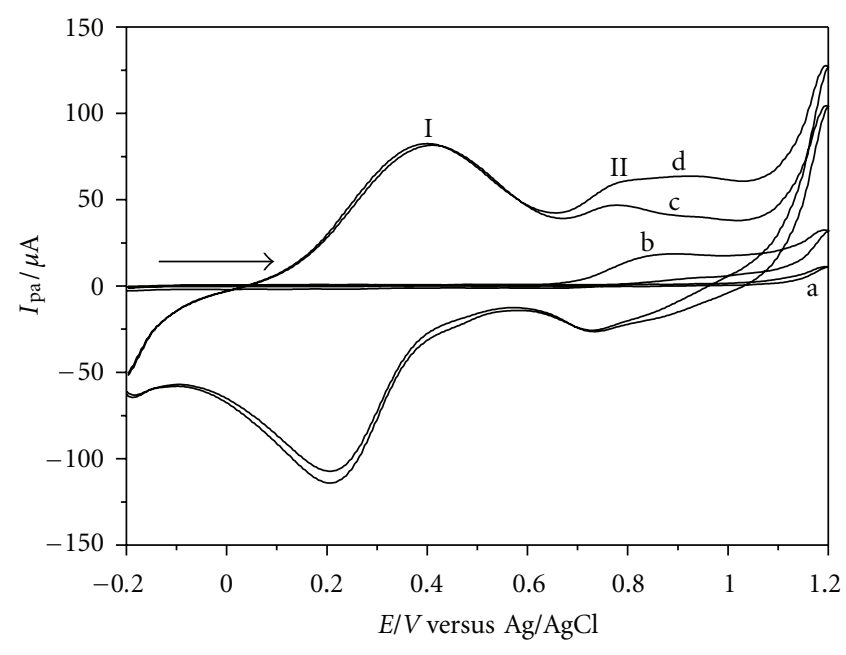

FIGURE 7: Voltammetric behavior of (a) graphite paste electrode, (b) graphite paste electrode in $1.0 \times 10^{-3} \mathrm{~mol} \mathrm{~L}^{-1}$ nitrite, (c) CuNPSD-modified graphite paste electrode, and (d) CuNPSDmodified graphite paste in the presence of $1.0 \times 10^{-3} \mathrm{~mol} \mathrm{~L}^{-1}$ of nitrite $\left(\mathrm{KCl}=1.0 \mathrm{~mol} \mathrm{~L}^{-1} ; v=20 \mathrm{mV} \mathrm{s}^{-1}\right)$.

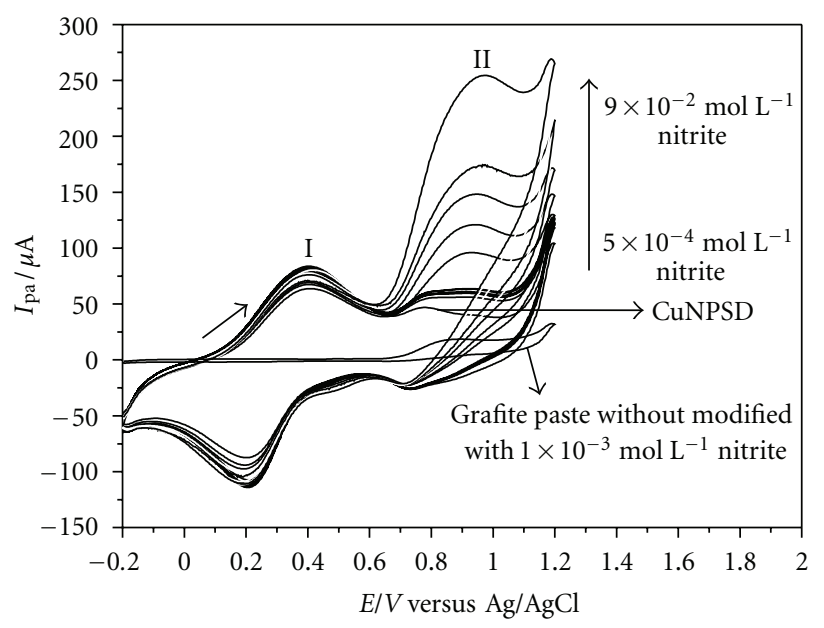

Figure 8: Cyclic voltammograms obtained for the CuNPSDmodified graphite paste electrode in the presence of different concentrations of nitrite $\left(5.0 \times 10^{-5}\right.$ to $9.0 \times 10^{-3} \mathrm{~mol} \mathrm{~L}^{-1}, \mathrm{KCl}=$ $\left.1.0 \mathrm{~mol} \mathrm{~L}^{-1} ; \mathrm{pH}=7.0 ; v=20 \mathrm{mV} \mathrm{s}^{-1}\right)$.

present the cyclic voltammograms of the graphite paste electrode modified with CuNPSD (CuNPSD-GPE) and without CuNPSD, respectively. On addition of nitrite (Figure 7(d)), the anodic current intensity of CuNPS-GPE was observed to increase in peak II. This process was also noted to occur at a lower potential (about $80 \mathrm{mV}$ ) than that observed for graphite paste without CuNPS in the presence of 1.0 $\times 10^{-3} \mathrm{~mol} \mathrm{~L}^{-1}$ of nitrite (Figure $7(\mathrm{~b})$ ).

The increase in anodic current with the addition of sodium nitrite (Figure 8 ) is due to moderate electrocatalytic oxidation of the nitrite by the electron mediator, CuNPSD, as described in (3) and (4). The nitrite chemically reduces $\mathrm{Fe}$ (III) to $\mathrm{Fe}$ (II) during the anodic scan, which again is electrochemically oxidized to $\mathrm{Fe}(\mathrm{III})$. The chemical step of

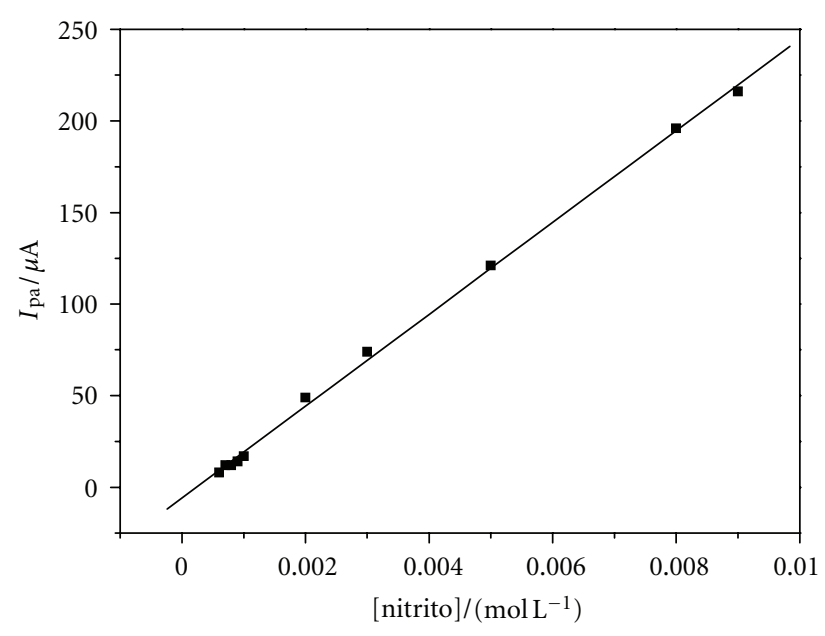

FIGURE 9: Analytical curve of the anodic peak (II) for the determination of nitrite using a CuNPSD-modified graphite paste electrode $\left(\mathrm{KCl}=1.0 \mathrm{~mol} \mathrm{~L}^{-1} ; \mathrm{pH}=7.0 ; v=20 \mathrm{mV} \mathrm{s}^{-1}\right)$.

the process $[42,43]$ at the interface of electrolyte solution is given by (4).

$$
\begin{gathered}
\mathrm{NO}_{2}{ }^{-}+\mathrm{H}_{2} \mathrm{O} \longrightarrow \mathrm{NO}_{3}{ }^{-}+2 \mathrm{H}^{+}+2 \mathrm{e}^{-} \\
\mathrm{Cu}^{(\mathrm{II})}\left[\mathrm{Fe}^{(\mathrm{III})}(\mathrm{CN})_{5} \mathrm{NO}\right]+\mathrm{K}^{+}+\frac{1}{2} \mathrm{NO}_{2}{ }^{-}+\frac{1}{2} \mathrm{H}_{2} \mathrm{O} \\
\longrightarrow \frac{1}{2} \mathrm{NO}_{3}{ }^{-}+\mathrm{H}^{+}+\mathrm{KCu}^{\mathrm{II}}\left[\mathrm{Fe}^{\mathrm{II}}(\mathrm{CN})_{5} \mathrm{NO}\right] .
\end{gathered}
$$

Figure 9 shows the analytical curve for the determination of the nitrite. From the curve, it is easy to observe that a linear system of $5.0 \times 10^{-4}$ to $9.0 \times 10^{-3} \mathrm{~mol}$ of nitrite has a corresponding analytical equation $Y(\mu \mathrm{A})$ $=-5.78+25060.97$ (nitrite) with a correlation coefficient of $r=0.9993$. The method was found to present a detection limit of $3.8 \times 10^{-4} \mathrm{~mol} \mathrm{~L}^{-1}$ with an amperometric sensitivity of $25.0 \mathrm{~mA} / \mathrm{mol} / \mathrm{L}$ for nitrite.

\section{Conclusions}

FTIR studies, along with EDX, confirm the modification of 3-chloropropylsilyl silica gel with DABAm-16 (SD), hexadecylamine poly (propylene) imine dendrimer. After two stages of synthesis, the modified silica, SD, was found to promote the formation of the binuclear compound, CuNPSD, subsequently characterized by voltammetric and spectroscopic techniques.

The CuNPSD-modified graphite paste electrode was found to show a good electrochemical stability and excellent response to the electrocatalytic oxidation of sodium nitrite with a detection limit of $3.8 \times 10^{-4} \mathrm{~mol} \mathrm{~L}^{-1}$ and an amperometric sensitivity of $25.0 \mathrm{~mA} / \mathrm{mol} \mathrm{L}^{-1}$. The use of CuNPSDmodified electrodes is advantageous because there is no need for any prior chemical treatment, and it is easily made, thus allowing the surface to be quickly renewed thereby decreasing the time spent in performing the analytical measurements. 


\section{References}

[1] G. R. Newkome, C. N. Moorefield, and F. Vogtle, Dendritic Macromolecules: Concepts, Syntheses, Perspectives, Wiley-VCH, New York, NY, USA, 1996.

[2] Z. Zhou, A. D’Emanuele, K. Lennon, and D. Attwood, “Synthesis and micellization of linear-dendritic copolymers and their solubilization ability for poorly water-soluble drugs," Macromolecules, vol. 42, no. 20, pp. 7936-7944, 2009.

[3] A. Gomez-Escudero, M. A. Azagarsamy, N. Theddu, R. W. Vachet, and S. Thayumanavan, "Selective peptide binding using facially amphiphilic dendrimers," Journal of the American Chemical Society, vol. 130, no. 33, pp. 11156-11163, 2008.

[4] K. K. Kline, E. J. Morgan, L. K. Norton, and S. A. Tucker, "Encapsulation and quantification of multiple dye guests in unmodified poly(amidoamine) dendrimers as a function of generation," Talanta, vol. 78, no. 4-5, pp. 1489-1491, 2009.

[5] D. Kannaiyan and T. Imae, "PH-Dependent encapsulation of pyrene in PPI-Core:PAMAM-shell dendrimers," Langmuir, vol. 25, no. 9, pp. 5282-5285, 2009.

[6] Y. Cheng, M. Li, and T. Xu, "Potential of poly(amidoamine) dendrimers as drug carriers of camptothecin based on encapsulation studies," European Journal of Medicinal Chemistry, vol. 43, no. 8, pp. 1791-1795, 2008.

[7] K. Didehban, H. Namazi, and A. A. Entezami, "Triazine-based dendrimers as liquid crystals: synthesis and characterization," Iranian Polymer Journal, vol. 18, no. 9, pp. 731-741, 2009.

[8] E. B. Bustos, M. G. G. Jiménez, B. R. Díaz-Sánchez, E. Juaristi, T. W. Chapman, and L. A. Godínez, "Glassy carbon electrodes modified with composites of starburst-PAMAM dendrimers containing metal nanoparticles for amperometric detection of dopamine in urine," Talanta, vol. 72, no. 4, pp. 1586-1592, 2007.

[9] M. A. González-Fuentes, J. Manríquez, R. Antaño-López, and L. A. Godínez, "Electrochemically driven transfer of carboxylterminated PAMAM dendrimers at the water/dichloroethane interface," Electrochemistry Communications, vol. 12, no. 1, pp. 137-139, 2010.

[10] S. Berchmans, T. M. Vergheese, A. L. Kavitha, M. Veerakumar, and V. Yegnaraman, "Electrochemical preparation of copperdendrimer nanocomposites: picomolar detection of $\mathrm{Cu} 2+$ ions," Analytical and Bioanalytical Chemistry, vol. 390, no. 3, pp. 939-946, 2008.

[11] I. Grabchev, S. Dumas, and J. M. Chovelon, "A polyamidoamine dendrimer as a selective colorimetric and ratiometric fluorescent sensor for Li+ cations in alkali media," Dyes and Pigments, vol. 82, no. 3, pp. 336-340, 2009.

[12] Z. Yang, B. Xu, J. He et al., "Solution-processable and thermalstable triphenylamine-based dendrimers with truxene cores as hole-transporting materials for organic light-emitting devices," Organic Electronics, vol. 10, no. 5, pp. 954-959, 2009.

[13] J. Ding, J. Lü, Y. Cheng et al., "Solution-processible red iridium dendrimers based on oligocarbazole host dendrons: synthesis, properties, and their applications in organic light-emitting diodes," Advanced Functional Materials, vol. 18, no. 18, pp. 2754-2762, 2008.

[14] T. Maiyalagan, "Pt-Ru nanoparticles supported PAMAM dendrimer functionalized carbon nanofiber composite catalysts and their application to methanol oxidation," Journal of Solid State Electrochemistry, vol. 13, no. 10, pp. 1561-1566, 2009.

[15] C.-M. Lo and H.-F. Chow, "Structural effects on the catalytic, emulsifying, and recycling properties of chiral amphiphilic dendritic organocatalysts," Journal of Organic Chemistry, vol. 74, no. 15 , pp. 5181-5191, 2009.
[16] A. C. Pereira, A. D. S. Santos, and L. T. Kubota, "Trends in amperometric electrodes modification for electroanalytical applications," Quimica Nova, vol. 25, no. 6, pp. 1012-1021, 2002.

[17] D. R. Do Carmo, R. M. Silva, and N. R. Stradiotto, Journal of the Brazilian Chemical Society, vol. 14, no. 4, pp. 616-620, 2003.

[18] D. R. Do Carmo, R. M. Silva, and N. R. Stradiotto, "Electrochemical behaviour of copper nitroprusside generated in situ onto the graphite paste electrode surface and its application in the determination of $\mathrm{N}$-acethylcsteine," Portugaliae Electrochimica Acta, vol. 23, p. 457, 2005.

[19] M. H. Pournaghi-Azar and H. Nahalparvari, "Preparation and characterization of electrochemical and electrocatalytic behavior of a zinc pentacyanonitrosylferrate film-modified glassy carbon electrode," Journal of Electroanalytical Chemistry, vol. 583, no. 2, pp. 307-317, 2005.

[20] H. M. Carapuça, O. M. S. Filipe, J. E. J. Simão, and A. G. Fogg, "Electrochemical studies of nitroprusside in the presence of copper(II): formation of $\mathrm{Cu}(\mathrm{I})$ reduced nitroprusside species," Journal of Electroanalytical Chemistry, vol. 480, no. 1-2, pp. 8493, 2000

[21] F. C. Pereira and M. V. B. Zanoni, "Electrochemical reduction of nitroprusside on a glassy carbon electrode modified by poly-l-lysine films," Journal of Solid State Electrochemistry, vol. 12, no. 1, pp. 63-70, 2008.

[22] H. Razmi and H. Heidari, "Nafion/lead nitroprusside nanoparticles modified carbon ceramic electrode as a novel amperometric sensor for 1-cysteine," Analytical Biochemistry, vol. 388, no. 1, pp. 15-22, 2009.

[23] H. Razmi and E. Habibi, "Nanomolar detection of hydrogen peroxide at a new polynuclear cluster of tin pentacyanonitrosylferrate nanoparticle-modified carbon ceramic electrode," Analytical Biochemistry, vol. 392, no. 2, pp. 126-132, 2009.

[24] D. R. Do Carmo, R. M. Silva, S. Gabriel Jr., U. O. Bicalho, A. A. Picon, and L. L. Paim, Macromolecular Symposia, vol. 299, pp. 206-214, 2011.

[25] S. Stevelmans, J. C. M. Van Hest, J. F. G. A. Jansen, D. A. F. J. Van Boxtel, E. M. M. De Brabander-van Den Berg, and E. W. Meijer, "Synthesis, characterization, and guest-host properties of inverted unimolecular dendritic micelles," Journal of the American Chemical Society, vol. 118, no. 31, pp. 7398-7399, 1996.

[26] H. P. Rang, Farmacologia, Elsevier, Rio de Janeiro, Brazil, 2004.

[27] J. B. Raoof, R. Ojani, and M. Ramine, "Voltammetric sensor for nitrite determination based on its electrocatalytic reduction at the surface of $\mathrm{p}$-duroquinone modified carbon paste electrode," Journal of Solid State Electrochemistry, vol. 13, no. 9, pp. 1311-1319, 2009.

[28] US Pharmacopeia USP 30 NF 25. Rockville: [s,n,], CD-Room, 2007.

[29] Farmacopéia Portuguesa VII, vol. 453, Imprensa Nacional de Lisboa, Lisbon, Portugal, 2002.

[30] A. I. Vogel, Análise Química Quantitativa, Livros Técnicos e Científicos- LTC, Rio de Janeiro, Brazil, 2005.

[31] I. M. P. L. V. O. Ferreira and S. Silva, "Quantification of residual nitrite and nitrate in ham by reverse-phase high performance liquid chromatography/diode array detector," Talanta, vol. 74, no. 5, pp. 1598-1602, 2008.

[32] N. Zhu, Q. Xu, S. Li, and H. Gao, "Electrochemical determination of nitrite based on poly(amidoamine) dendrimer-modified carbon nanotubes for nitrite oxidation," Electrochemistry Communications, vol. 11, no. 12, pp. 2308-2311, 2009. 
[33] A. Gomez, J. Rodriguez Hernandez, and J. E. Reguera, "Unique coordination in metal nitroprussides: the structure of $\mathrm{Cu}[\mathrm{Fe}(\mathrm{CN}) 5 \mathrm{NO}] \cdot 2 \mathrm{H} 2 \mathrm{O}$ and $\mathrm{Cu}[\mathrm{Fe}(\mathrm{CN}) 5 \mathrm{NO}]$," Journal of Chemical Crystallography, vol. 34, no. 12, pp. 893-903, 2004.

[34] S. W. Liang, M. X. Li, M. Shao, and H. J. Lui, "Cyanobridged bimetallic complexes based on nitroprusside $\left[\mathrm{Fe}(\mathrm{CN})_{5}(\mathrm{NO})\right]^{2-}$ and $[\mathrm{Cu}(\mathrm{TAAB}-\text { macrocycle })]^{2+}$ : Synthesis, structure and thermal stability," Journal of Molecular Structure, vol. 841, no. 1-3, pp. 73-77, 2007.

[35] D. R. Shankaran and S. S. Narayanan, "Characterisation and application of an electrode modified by mechanically immobilized copper hexacyanoferrate," Fresenius' Journal of Analytical Chemistry, vol. 364, pp. 686-689, 1999.

[36] A. C. De Sá, L. L. Paim, U. O. Bicalho, and D. R. Do Carmo, "Determination of $\mathrm{N}$-acetylcysteine by cyclic voltammetry using modified carbon paste electrode with copper nitroprusside adsorbed on the 3 aminopropylsilica," International Journal of Electrochemical Science, vol. 6, pp. 3754-3767, 2011.

[37] D. R. Do Carmo, R. M. Da Silva, and N. R. Stradiotto, "Electrochemical behaviour of copper nitroprusside generated in situ onto the graphite paste electrode surface, and its application in determination of n-acetylcysteine," Portugaliae Electrochimica Acta, vol. 23, no. 4, pp. 457-470, 2005.

[38] V. D. Ivanov and M. M. Kaplun, Elektrokhimiya, vol. 34, p. 560, 1998.

[39] D. R. Do Carmo, R. M. Silva, and N. R. Stradiotto, "Estudo eletroquímico de $\mathrm{Fe}[\mathrm{Fe}(\mathrm{CN}) 5 \mathrm{NO}]$ em eletrodo de pasta de grafite," Eclética Química, vol. 27, p. 197, 2002.

[40] A. P. Baioni, M. Vidotti, P. A. Fiorito, and S. I. Córdoba de Torresi, "Copper hexacyanoferrate nanoparticles modified electrodes: a versatile tool for biosensors," Journal of Electroanalytical Chemistry, vol. 622, no. 2, pp. 219-224, 2008.

[41] A. J. Bard and L. R. Faulkner, Electrochemical Methods: Fundamentals and Applications, John Wiley \& Sons, New York, NY, USA, 2nd edition, 1980.

[42] R. Guidelli, F. Pergola, and G. Raspi, "Voltammetric behavior of nitrite ion on platinum in neutral and weakly acidic media," Analytical Chemistry, vol. 44, no. 4, pp. 745-755, 1972.

[43] I. G. Casella and A. M. Salvi, "Voltammetric behavior and ion chromatographic detection of nitrite at a dispersed platinum glassy carbon electrode," Electroanalysis, vol. 9, no. 8, pp. 596601, 1997. 


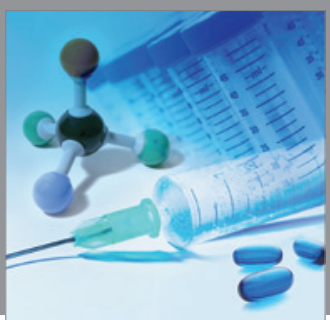

International Journal of

Medicinal Chemistry

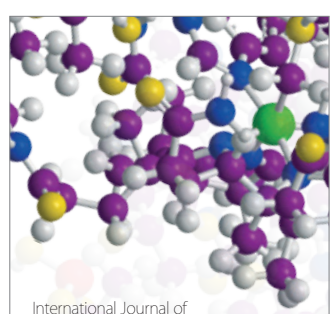

Carbohydrate Chemistry

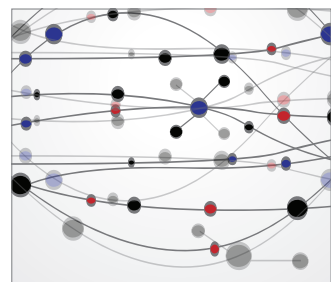

The Scientific World Journal
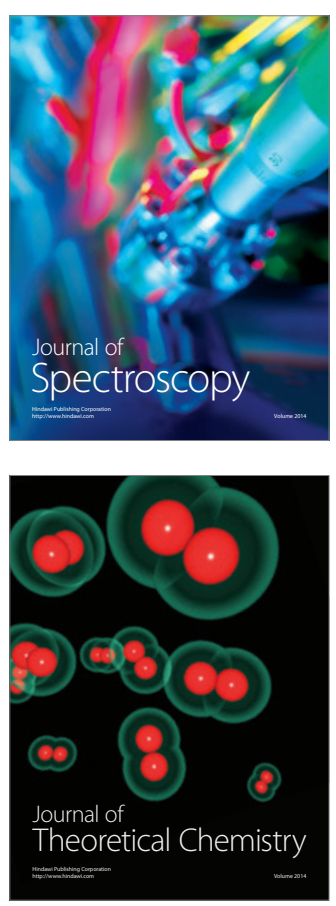
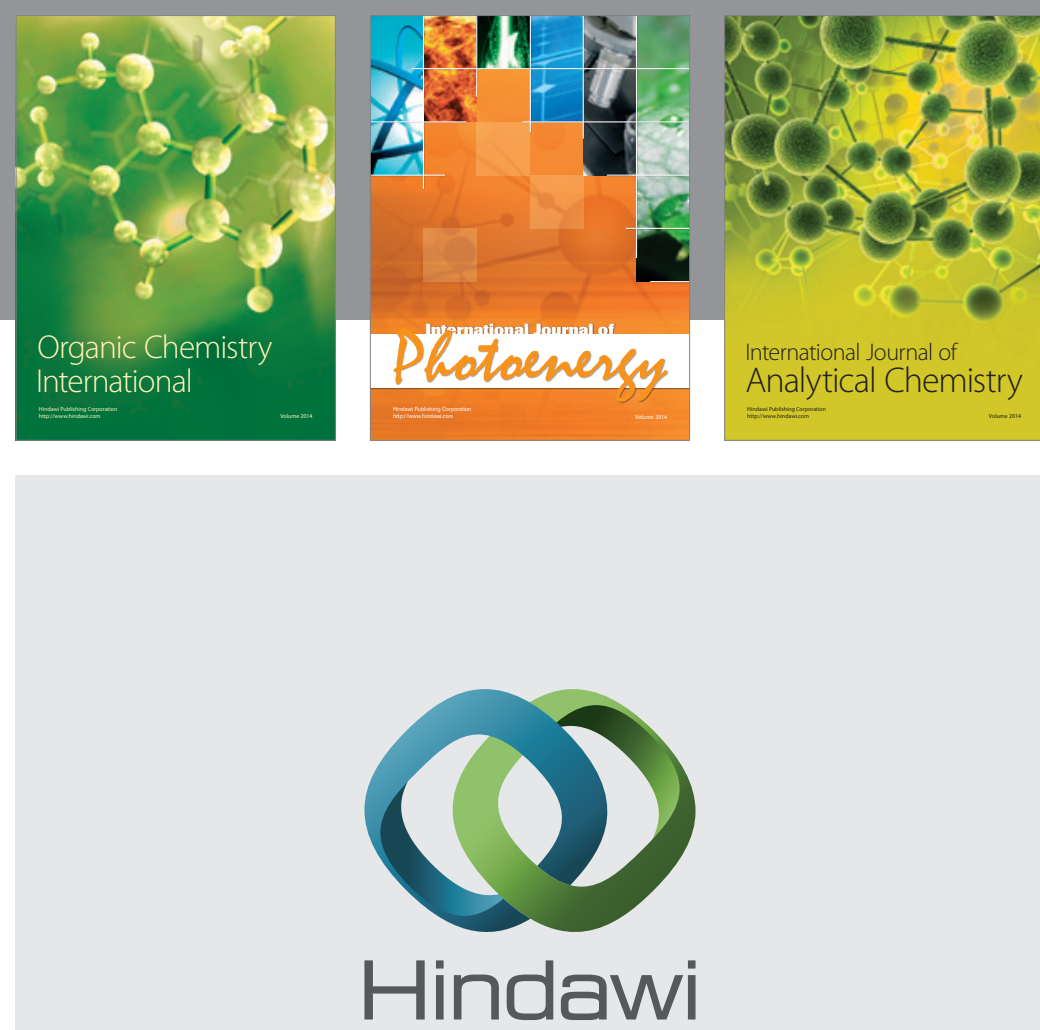

Submit your manuscripts at

http://www.hindawi.com
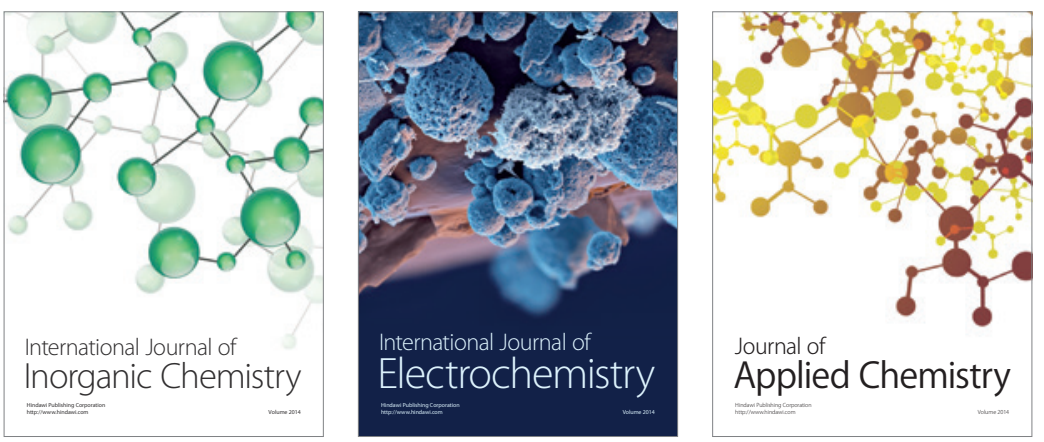

Journal of

Applied Chemistry
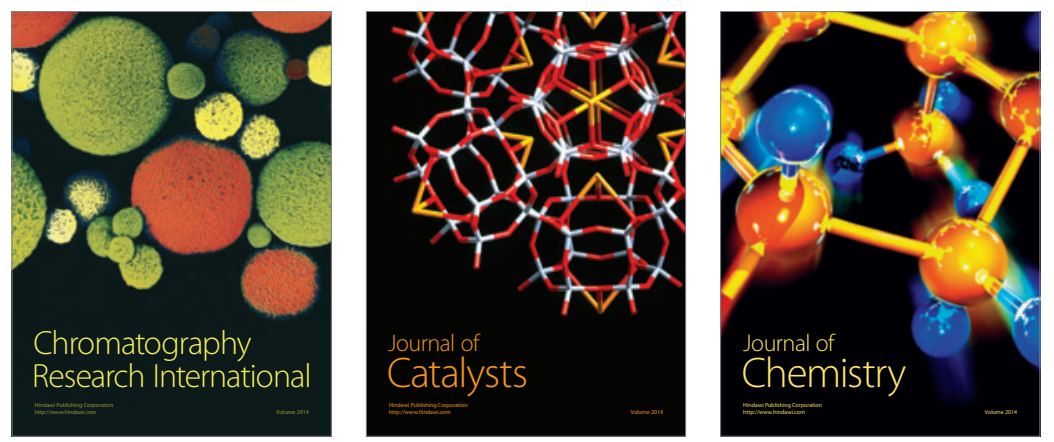
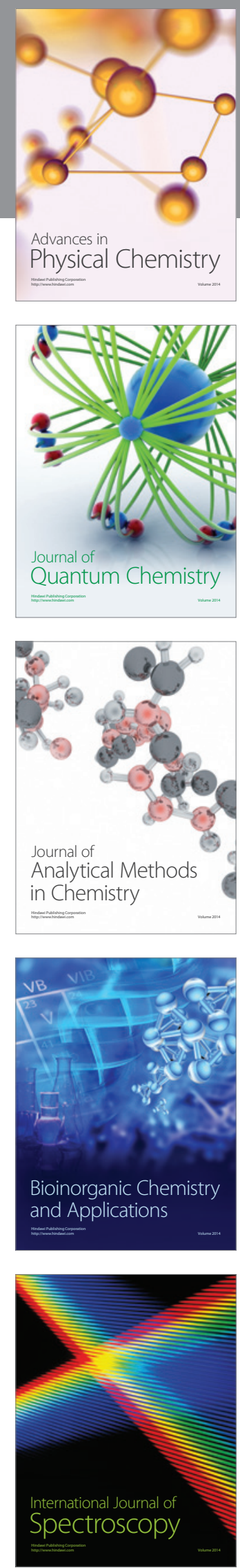